\title{
Author Correction: Dipeptidyl peptidase-4 inhibitors and cancer risk in patients with type 2 diabetes: a meta-analysis of randomized clinical trials
}

\section{Ming Zhao ${ }^{1,2}$, Jiayi Chen ${ }^{1}$, Yanyan Yuan ${ }^{1}$, Zuquan Zou ${ }^{1}$, Xiaolong Lai ${ }^{1}$, Daud M Rahmani ${ }^{1}$, Fuyan Wang ${ }^{1}$, Yang Xi ${ }^{1}$, Qin Huang ${ }^{3}$ \& Shizhong Bu ${ }^{1}{ }^{1}$}

Scientific Reports 7:8273; doi:10.1038/s41598-017-07921-2; Article published online 15 August 2017

The original version of this Article omitted an affiliation for Ming Zhao. The correct affiliations for Ming Zhao are listed below:

Runliang Diabetes Laboratory, Diabetes Research Center, School of Medicine, Ningbo University, 315211, Ningbo, China.

Department of Public Health, Longsai Hospital, 315200, Ningbo, China.

This has now been corrected in the HTML and PDF versions of this Article, and in the accompanying Supplemental Material.

(1) Open Access This article is licensed under a Creative Commons Attribution 4.0 International License, which permits use, sharing, adaptation, distribution and reproduction in any medium or format, as long as you give appropriate credit to the original author(s) and the source, provide a link to the Creative Commons license, and indicate if changes were made. The images or other third party material in this article are included in the article's Creative Commons license, unless indicated otherwise in a credit line to the material. If material is not included in the article's Creative Commons license and your intended use is not permitted by statutory regulation or exceeds the permitted use, you will need to obtain permission directly from the copyright holder. To view a copy of this license, visit http://creativecommons.org/licenses/by/4.0/.

(c) The Author(s) 2017

${ }^{1}$ Runliang Diabetes Laboratory, Diabetes Research Center, School of Medicine, Ningbo University, 315211, Ningbo, China. ${ }^{2}$ Department of Public Health, Longsai Hospital, 315200, Ningbo, China. ${ }^{3}$ Department of Endocrinology, Changhai Hospital, Second Military Medical University, 200433, Shanghai, China. Correspondence and requests for materials should be addressed to Q.H. (email: qxinyi1220@163.com) or S.B. (email: bushizhongbu@nbu.edu.cn) 